\title{
UM CURSO DE EDUCAÇÃO AMBIENTAL PARA PROFESSORES DA EDUCAÇÃO BÁSICA E A QUESTÃO DA CONTEXTUALIZAÇÃO DO ENSINO COMO DIRETRIZ METODOLÓGICA ${ }^{1}$
}

\author{
Danilo Seithi Kato ${ }^{2}$ \\ Natalia Vieira de Carvalho ${ }^{3}$ \\ Clarice Sumi Kawasaki ${ }^{4}$
}

Resumo: O presente trabalho identifica e analisa as concepções de contextualização do ensino (CE) presentes em um curso de educação ambiental voltado para professores da educação básica do município de Batatais (SP), a partir da avaliação do projeto pedagógico desse curso e das sequências didáticas produzidas pelos professores participantes. A questão da CE surge em função da organização da proposta a partir de temas de Ciências em uma abordagem contextualizada e regionalizada. Esta pesquisa desenvolve-se por meio de uma abordagem qualitativa da pesquisa educacional, analisando-se o conteúdo dos textos relacionados ao curso com base em uma categorização proposta por Kato e Kawasaki (2011). Os resultados demonstram que, apesar de o projeto pedagógico propor a CE em suas variadas perspectivas, o mesmo não acontece com as sequências didáticas produzidas pelos professores participantes, que em sua maioria apresentam concepções de CE voltadas para o cotidiano do aluno.

Palavras-chave: Educação ambiental. Temas de Ciências. Contextualização do ensino. Formação continuada de professores.

\section{AN ENVIRONMENTAL EDUCATION COURSE FOR ELEMENTARY SCHOOL TEACHERS AND THE ISSUE OF CONTEXTUALIZATION OF TEACHING AS A METHODOLOGICAL GUIDELINE}

\begin{abstract}
This study seeks to identify conceptions on contextualization of teaching (CT) in an environmental education course intended for elementary school teachers from the city of Batatais (São Paulo). The identification process is based on the analysis of the course education program and the teaching sequences produced by the participating teachers. The CT issue has emerged due to the nature of the proposal, which consists of science subjects approached in a contextualized and regionalized way. This research follows a qualitative approach of educational research and uses the categorization proposed by Kato and Kawasaki (2011). The results show that, although the course education program presents a variety of perspectives of CT, most of the teaching sequences developed by the teachers reveal a conception of CT focused on students' daily life.
\end{abstract}

\footnotetext{
1 Este trabalho resulta de aprofundamentos de artigo apresentado no VI Encontro de Pesquisa em Educação Ambiental (EPEA), realizado na USP-RP em 2011.

2 Departamento de Biologia da Faculdade de Filosofia, Ciências e Letras de Ribeirão Preto. , Universidade de São Paulo(USP), Ribeirão Preto, São Paulo, Brasil, kato@fffclrp.usp.br

${ }^{3}$ Licenciada em Ciências Biológicas pelo Centro Universitário Claretiano de Batatais. Especialista em Ensino de Ciências por Investigação. Centro de Ensino de Ciências e Matemática - CECIMIG, Universidade Federal de Minas Gerais (UFMG), Minas Gerais, Brasil, nvcbio@gmail.com

${ }^{4}$ Departamento de Educação, Informação e Comunicação da Faculdade de Filosofia, Ciências e Letras de Ribeirão Preto, Universidade de São Paulo (USP), Ribeirão Preto, São Paulo, Brasil, sumi@ffclrp.usp.br
} 
Keywords: Environmental Education. Science themes. Contextualization of teaching. Teacher continuing education.

\section{UN CURSO DE EDUCACIÓN AMBIENTAL PARA PROFESORES DE EDUCACIÓN BÁSICA Y LA CUESTIÓN DE LA CONTEXTUALIZACIÓN DE LA ENSEÑANZA COMO DIRECTRIZ METODOLÓGICA}
Resumen: El presente trabajo identifica y analiza las concepciones de contextualización de la enseñanza (CE) presentes en un curso de educación ambiental dirigido a profesores de educación básica del municipio de Batatais (SP), a partir de la evaluación del proyecto pedagógico de este curso y de las secuencias didácticas producidas por los profesores participantes. La cuestión de la CE surge en función de la organización de la propuesta a partir de temas de Ciencias en un abordaje contextualizado y regionalizado. Esta investigación se desarrolló por medio de un abordaje cualitativo de la investigación educacional, analizando el contenido de los textos relacionados al curso con base en una categorización propuesta por Kato y Kawasaki (2011). Los resultados demuestran que, a pesar de que el proyecto pedagógico propone la CE en sus variadas perspectivas, lo mismo no acontece con las secuencias didácticas producidas por los profesores participantes que, en su mayoría, presentan concepciones de CE dirigidas al cotidiano del alumno.

Palabras clave: Educación ambiental. Temas de Ciencias. Contextualización de la enseñanza. Formación continuada de profesores.

\section{Introdução}

A inserção da educação ambiental (EA) no currículo escolar tem sido objeto de discussão e polêmicas há algum tempo. Apesar de superada a ideia da criação de uma disciplina específica sobre o tema, na prática os professores ainda encontram muitas dificuldades para propor formas alternativas a esse modelo disciplinar. O sistema de ensino organizado a partir de um currículo no qual as disciplinas escolares são desenvolvidas de forma fragmentada, reforçada pela formação especializada dos professores, mostra-se muitas vezes incompatível com a demanda de uma EA que vislumbre a perspectiva inter ou transdisciplinar, que busque a complexidade do ambiente e que esteja vinculada aos aspectos sociais, culturais e econômicos da realidade do aprendiz.

A integração dos conteúdos escolares e de áreas do conhecimento envolvendo a temática ambiental com a EA demanda novos olhares, novos contextos de significação e uma articulação com questões regionais, que façam sentido aos sujeitos envolvidos nos processos educativos (GUIMARÃES, 2007). É nessa perspectiva que a abordagem contextualizada e regionalizada de temas de Ciências para um curso de educação ambiental passa a fazer sentido, tornando-se a principal diretriz metodológica para um curso que foi desenvolvido para professores de diferentes áreas de ensino da educação básica de Batatais (SP).

A proposta do presente artigo é apresentar os resultados de uma pesquisa desenvolvida a partir de um curso de formação continuada para professores da educação básica. As concepções 
de CE presentes nesse curso foram identificadas com base na análise do seu projeto pedagógico e das sequências didáticas desenvolvidas pelos professores participantes. É importante ressaltar que a CE é uma das diretrizes metodológicas desse curso. A partir desse objetivo geral, busca-se: identificar as diferentes concepções de contextualização do ensino (CE) presentes nesse curso e discutir as suas implicações pedagógicas para a organização do trabalho docente na articulação de conteúdos de áreas específicas com temas de educação ambiental. Os aspectos das relações entre duas áreas do conhecimento escolar - o ensino de Ciências e EA - são também foco de discussão neste trabalho.

$\mathrm{Na}$ primeira parte, apresentaremos a pesquisa realizada por Kato e Kawasaki (2011), destacando a relevância de estudos sobre a CE, bem como um breve relato da pesquisa desenvolvida e a categorização proposta por estes autores para a identificação e análise das concepções de CE. Apesar de a referida pesquisa ter sido desenvolvida no contexto do ensino de Ciências e de Biologia, entendemos ser possível transpor a categorização proposta para este estudo. As implicações dessa transposição também serão foco destas discussões.

$\mathrm{Na}$ segunda parte, apresentaremos o projeto pedagógico do curso de educação ambiental "Meio ambiente e você professor: uma rede de saberes", quanto aos seus objetivos, público-alvo e desenvolvimento, para situar o contexto do presente trabalho. Em seguida, será descrita a metodologia utilizada nesta pesquisa.

$\mathrm{Na}$ terceira parte, identificaremos os aspectos relacionados à $\mathrm{CE}$ do projeto pedagógico do curso e das sequências didáticas produzidas pelos professores participantes, para analisá-los à luz da categorização proposta por Kato e Kawasaki (2011). As discussões sobre as implicações pedagógicas dessas concepções de CE para as práticas educativas finalizarão o presente trabalho.

\section{As pesquisas sobre a "contextualização do ensino" e o referencial teórico de análise adotado neste trabalho}

Apesar do termo "contextualização do ensino" (CE) ter sido mais explicitamente apresentado nas DCNEM (BRASIL, 1998), o seu significado para a educação formal não é novo. Sob diferentes denominações ou até mesmo sem uma referência mais explícita, essa noção já vinha sendo abordada por diferentes autores.

Para Rodrigues e Amaral (1996), contextualizar o ensino significa trazer à tona a própria realidade do aluno, não apenas como ponto de partida para o processo de ensino e aprendizagem mas como o próprio contexto do ensino. Para Moysés (1997), trazer os contextos de vivência dos alunos para os contextos de aprendizagem torna-se um importante fator de aprendizagem, pois isso dá sentido aos conhecimentos apreendidos. Para Lima et al. (2000), a contextualização do ensino ocorre quando são considerados os conhecimentos prévios e o cotidiano dos alunos. Segundo Moura, Garcia e Ramos (2007), a contextualização do ensino é um recurso para ampliar as possibilidades de interação não apenas das disciplinas nucleadas em uma área de conhecimento (as próprias áreas de nucleação) como também desses conhecimentos com a realidade do aluno.

Lopes, Gomes e Lima (2001) analisam, no texto oficial dos Parâmetros Curriculares Nacionais do Ensino Médio (BRASIL, 1998), as relações entre os conteúdos das diversas disciplinas da área de Ciências da Natureza, Matemática e suas Tecnologias e os contextos de vida dos alunos, procurando saber quais são aqueles considerados importantes em cada uma dessas disciplinas. Nesse trabalho, identificam um misto de concepções, mas que, em síntese, evidenciam a ideia de aproximação dos conteúdos científicos ao cotidiano do aluno, estreitando essa relação e produzindo conhecimento no ambiente escolar. Lopes (2002), ao procurar entender a influência do discurso curricular oficial sobre a produção do conhecimento escolar, 
identifica a presença de um discurso curricular híbrido nos PCNEM (BRASIL, 1999) e o caráter ambíguo do conceito de contextualização. Nesse discurso híbrido, analisa as ambiguidades expressas pelo conceito de contextualização no conhecimento oficial, destacando três interpretações para "contexto" nas orientações curriculares para o ensino médio: a) trabalho; b) cidadania; c) vida pessoal, cotidiana e convivência.

Kato e Kawasaki (2011), ao analisarem os documentos curriculares oficiais de Ciências e de Biologia e a fala de professores de Ciências durante o desenvolvimento de oficinas em um curso de formação continuada, identificam uma variedade de significados atribuídos ao termo "contextualização do ensino". Foram identificadas dez concepções de CE, que então foram organizadas em cinco categorias de análise, conforme mostra o Quadro 1. Observou-se que, apesar da multiplicidade de concepções de CE, estas não são contraditórias entre si (ou ambíguas), já que todas compartilham da noção de que contextualizar é articular ou situar o conhecimento específico da disciplina (parte) em contextos mais amplos de significação (todo), estes, sim, bastante variados: o cotidiano do aluno, a(s) disciplina(s) escolar(es), a ciência (referência), o ensino e os contextos histórico, social e cultural. Concluem, assim, que essa diversidade de concepções de $\mathrm{CE}$ pode oferecer ao professor possibilidades múltiplas de mediações didáticas em sua difícil tarefa de planejar e organizar o ensino, desde que essas concepções sejam explicitadas e exploradas por ele nos processos de transposição do ensino. Algumas dessas possibilidades são abordadas no texto, por meio de uma discussão sobre as implicações pedagógicas de cada uma dessas diferentes concepções de CE encontradas.

\begin{tabular}{|c|c|c|c|}
\hline $\begin{array}{l}\text { CATEGORIAS DE } \\
\text { ANÁLISE }\end{array}$ & CONCEPÇÕES & $\begin{array}{l}\text { CONTEXTOS DE } \\
\text { SIGNIFICAÇÃO }\end{array}$ & $\begin{array}{c}\text { DOCUMENTOS } \\
\text { OU } \\
\text { PROFESSORES }\end{array}$ \\
\hline \multirow[t]{2}{*}{$\begin{array}{l}\text { 1) COTIDIANO DO } \\
\text { ALUNO }\end{array}$} & $\begin{array}{l}\text { Buscar relações com as } \\
\text { experiências pessoais e sociais } \\
\text { do aluno, a realidade do aluno e } \\
\text { a cidadania. }\end{array}$ & Cotidiano do aluno & $\begin{array}{l}\text { DCNEM/ } \\
\text { PCNEM/PCEB/ } \\
\text { PCNEF/PCEC/ } \\
\text { MRCC } \\
\text { PROFESSORES }\end{array}$ \\
\hline & $\begin{array}{l}\text { Buscar relações com o mundo } \\
\text { do trabalho. }\end{array}$ & Mundo do trabalho & DCNEM \\
\hline $\begin{array}{l}\text { 2) DISCIPLINA(S) } \\
\text { ESCOLAR(ES) }\end{array}$ & $\begin{array}{l}\text { Buscar relações com outras } \\
\text { disciplinas (multi, trans ou } \\
\text { interdisciplinaridade). }\end{array}$ & $\begin{array}{l}\text { Outras disciplinas } \\
\text { escolares }\end{array}$ & $\begin{array}{l}\text { DCNEM/ } \\
\text { PCNEM/ } \\
\text { PCNEF/PCEC } \\
\text { PROFESSORES }\end{array}$ \\
\hline \multirow[t]{2}{*}{ 3) CIÊNCIA } & $\begin{array}{l}\text { Buscar relações com a ciência, } \\
\text { enquanto produto e processo. }\end{array}$ & Universo da ciência & PCNEM/PCEC \\
\hline & $\begin{array}{l}\text { Buscar relaçōes com as } \\
\text { ciências naturais, em especial a } \\
\text { ciências biológicas (as teorias } \\
\text { evolutivas). }\end{array}$ & $\begin{array}{l}\text { Teorias gerais da } \\
\text { Biologia e da ciência }\end{array}$ & PCEB \\
\hline \multirow[t]{2}{*}{ 4) ENSINO } & $\begin{array}{l}\text { Buscar relações entre } \\
\text { conhecimento científico e } \\
\text { conhecimento escolar. }\end{array}$ & $\begin{array}{l}\text { Conhecimento } \\
\text { científico }\end{array}$ & PCNEM \\
\hline & $\begin{array}{l}\text { Buscar problematizar e situar o } \\
\text { conhecimento escolar em } \\
\text { relação a outras formas de } \\
\text { conhecimento. }\end{array}$ & $\begin{array}{l}\text { Diversas formas de } \\
\text { conhecimento em } \\
\text { diferentes contextos }\end{array}$ & $\begin{array}{l}\text { PCNEF/PCEC/ } \\
\text { MRCC }\end{array}$ \\
\hline \multirow{3}{*}{$\begin{array}{l}\text { 5) CONTEXTO } \\
\text { HISTÓRICO, } \\
\text { SOCIAL E } \\
\text { CULTURAL }\end{array}$} & $\begin{array}{l}\text { Buscar relações com elementos } \\
\text { da cultura. }\end{array}$ & $\begin{array}{l}\text { Cultura brasileira e } \\
\text { mundial }\end{array}$ & $\begin{array}{l}\text { PCNEM/PCNEF/ } \\
\text { PCEC } \\
\text { PROFESSORES }\end{array}$ \\
\hline & $\begin{array}{l}\text { Buscar relações com a história } \\
\text { da ciência. }\end{array}$ & $\begin{array}{l}\text { Contexto histórico e } \\
\text { social }\end{array}$ & PCNEM/PCEC \\
\hline & Buscar relações CTS & $\begin{array}{l}\text { Ciência, tecnologia e } \\
\text { sociedade }\end{array}$ & $\begin{array}{l}\text { PCNEM/PCNEF/ } \\
\text { PCEC } \\
\text { PROFESSORES }\end{array}$ \\
\hline
\end{tabular}

Quadro 1. Categorias de análise das concepções de contextualização do ensino.

\footnotetext{
DCNEM (1998) - Diretrizes Curriculares Nacionais para o Ensino Médio.

PCNEM (1999) - Parâmetros Curriculares Nacionais para o Ensino Médio.

PCEB (1988) - Proposta Curricular para o Ensino de Biologia.
} 
PCNEF (1998) - Parâmetros Curriculares Nacionais para o Ensino Fundamental.

PCEC (1991) - Proposta Curricular para o Ensino de Ciências e Programas de Saúde.

MRCC (1992) - Movimento de Reorientação Curricular - Ciências.

\section{O curso de educação ambiental "Meio ambiente e você professor: uma rede de saberes"}

Esse curso foi proposto pelo BATEA, que é um núcleo de educação ambiental criado e executado pela equipe do Centro de Estudos e Extensão da Floresta da USP (CEEFLORUSP), em parceria com a Fundação José Lazzarini. A finalidade desse núcleo é promover ações educativas relacionadas às questões socioambientais do município de Batatais, $\mathrm{SP}$, tendo como um dos principais focos a formação de agentes multiplicadores. O curso de formação continuada de professores da educação básica foi proposto com o objetivo de introduzir a EA em suas práticas educativas, a partir de temas de Ciências - biodiversidade, água e energia - e uma abordagem contextualizada e interdisciplinar dos conteúdos escolares, sendo o contexto regional um dos enfoques mais importantes dessa abordagem.

O curso foi desenvolvido por uma equipe multidisciplinar (Biologia, Química, Física, Medicina, Psicologia, Pedagogia, História, Filosofia, Letras e Matemática) de dez profissionais, a qual planejou e organizou todas as oficinas, o material de apoio e os recursos didáticos de forma coletiva. A formação multidisciplinar da equipe pedagógica e o plano de aula compartilhado visavam à promoção de uma EA contextualizada e interdisciplinar, que através de diferentes olhares buscasse uma visão mais integrada das questões socioambientais.

A metodologia empregada, de enfoque interdisciplinar, visava adotar os temas socioambientais como eixos unificadores dos conteúdos das diversas áreas do conhecimento escolar. Entre as várias correntes pedagógicas em EA, conforme identifica Sauvè (2005), destacou-se um modelo de intervenção no qual a contextualização dos temas e a importância do diálogo dos saberes (científicos, formais, cotidianos, tradicionais etc.) com enfoque crítico são diretrizes metodológicas fundamentais para as práticas educativas.

Para promover esse modelo de intervenção, que não poderia realizar-se através dos moldes tradicionais de ensino (DIAS, 2004), foi preciso considerar a realidade socioeconômicocultural do professor cursista, além de promover o ensino por meio de vivências e experimentações, afinal, a experiência é uma condição para a produção de sentido e este é produzido nas experiências do sujeito (CARVALHO, 2006). A preocupação com a contextualização surge nesse contexto, a fim de garantir ao aprendiz subsídios para compreender as relações que mantém com o meio, entendendo-se como parte dele e, assim, participando ativamente do meio social em que está inserido.

No primeiro módulo, que envolveu 50 professores das escolas municipais dos ensinos fundamental e médio de Batatais, durante dez sábados consecutivos, o objetivo foi apresentar temas ambientais a partir da problematização de suas questões sociais, econômicas e culturais. A primeira parte das oficinas foi embasada por documentos e trabalhos acadêmicos que permitiram essa problematização, envolvendo principalmente as questões ligadas ao município e à escola. A contextualização dos temas abordados nas situações reais do município foi feita a partir de um documento oficial, fornecido pelo Ministério Público, que descrevia alguns problemas ambientais em que a cidade estava inserida. O plano diretor e os estudos técnicos oficiais realizados pela Prefeitura forneceram dados sobre as microbacias locais, os aspectos energéticos e de risco ambiental. Na segunda parte da oficina, os professores participantes organizaram-se em pequenos grupos e discutiram e elaboraram ações e propostas a partir dessas reflexões.

O segundo módulo do curso foi desenvolvido sob os mesmos moldes do primeiro, porém com direcionamento maior para os seguintes temas: a Diversidade (tanto a biológica 
quanto a cultural, incluindo as questões de sexualidade e de gênero); a Água (incluindo a questão geopolítica, o uso e consumo); a Energia (incluindo o conceito científico de energia, as matrizes energéticas e o aquecimento global); a Avaliação (incluindo discussão sobre avaliação democrática). Na primeira parte buscou-se discutir e aprofundar esses temas e na segunda parte buscou-se a produção de materiais didáticos e de Sequências Didáticas. Nessa produção, que foi desenvolvida por grupos de professores participantes, foram confeccionadas "caixas temáticas" contendo as sequências didáticas, que foram disponibilizadas no Núcleo BATEA para uso público.

Havia nesse curso uma perspectiva segundo a qual aos professores caberia o papel de diagnosticar e interpretar problemas locais e suas múltiplas implicações para o cotidiano (LEME, 2006 , p. 110), ao passo que os alunos teriam o papel de promover discussões sobre assuntos de sua realidade, criando assim oportunidades para que se posicionassem sobre as questões que estão à sua volta e aplicassem esse conhecimento.

\section{Metodologia da pesquisa}

Os dados desta pesquisa foram obtidos por meio de uma análise de conteúdo (BARDIN, 2009) dos textos do projeto pedagógico do referido curso de EA e das sequências didáticas elaboradas pelos professores participantes.

O projeto pedagógico do curso está organizado da seguinte forma: Introdução, Objetivos e Justificativas, Metodologia e Estratégias Propostas, Cronograma de Execução e Bibliografia. A partir de uma análise documental, identificaram-se os principais objetivos e quais estratégias foram pensadas para o grupo de professores. O conteúdo e as estratégias pedagógicas adotadas geraram os resultados da presente pesquisa.

$\mathrm{Na}$ análise das sequências didáticas foram destacados os trechos dos textos nos quais o termo CE estava explicitado e em seguida os trechos que induziam à noção de CE, por apresentarem termos e/ou ideias com significados similares ou relacionados. Das dez sequências didáticas, produzidas no segundo módulo do curso, cinco foram selecionadas para uma primeira análise. Essa primeira seleção ocorreu após a leitura flutuante de todas as sequências didáticas e levou em conta a presença de alguns itens: objetivos, metodologia e concepções de contextualização do ensino expressas na proposta. Uma nova seleção foi feita destacando aquelas que possibilitavam uma identificação mais direta das concepções de CE, por meio de termos expressos e/ou relacionados à noção de CE, sendo reservadas para a análise final três sequências didáticas.

Para a análise e identificação das concepções de CE presentes no projeto pedagógico do curso e nas sequências didáticas ${ }^{5}$ produzidas pelos professores, utilizou-se a categorização proposta por Kato e Kawasaki (2011), conforme descrito anteriormente.

\section{Resultados}

De modo geral, as concepções de CE do projeto pedagógico (PP) do curso de EA analisado abrangem todas as perspectivas encontradas por Kato e Kawasaki (2011), quais sejam:

\footnotetext{
${ }^{5}$ Sequência didática (SD) é um planejamento para mais de uma atividade de ensino, uma proposta com objetivos e conteúdos bem delimitados, com adoção de estratégias para uma sequência de atividades em um tempo determinado. Segundo Zabala (1998), essa é uma unidade preferencial de análise da prática que permitirá o estudo e a avaliação de uma perspectiva processual, que inclua as fases de planejamento, aplicação e avaliação. $\mathrm{O}$ objetivo do curso foi utilizar esse mecanismo de produção de SD para promover a articulação dos diferentes saberes envolvidos em cada oficina do curso. A expectativa era de que os professores participantes pudessem elaborar propostas que contextualizassem o objeto de aprendizagem. Assim, a interdisciplinaridade e outras diretrizes relacionadas à abordagem da EA seriam planejadas, praticadas e avaliadas.
} 
o cotidiano do aluno, a(s) disciplina(s) escolar(es), a ciência (referência), o ensino e os contextos histórico, social e cultural.

Com relação ao projeto pedagógico do curso, foi possível identificar, a partir da análise documental, a intenção dos proponentes de utilizar a contextualização do ensino como diretriz metodológica para o estudo do meio ambiente. A concepção de meio ambiente apresentada no curso (mais especificamente na primeira atividade proposta) pauta-se pela perspectiva ampliada de ambiente, no sentido de não restringi-lo aos aspectos naturalísticos, ampliando-o para perspectivas culturais e econômicas relacionadas às questões do entorno de vivências dos participantes.

Uma ideia presente no PP é trazer um contexto significativo para os professores partindo da sua realidade de vivências e do seu cotidiano. As questões relacionadas ao seu município foram importantes pontos de partida para o curso. Buscando-se um enfoque regional dos temas do curso - diversidade, água e energia -, investigou-se nos documentos oficiais do município em questão (plano diretor e relatórios técnicos) como esses temas eram desenvolvidos e quais eram as principais questões e conflitos locais relacionados. Paralelamente, buscou-se um enfoque global desses mesmos temas, para compreender como questões locais e regionais estão sintonizadas com contextos mais globais.

Nesse sentido, a contextualização aparece como uma forma de representação do contexto de vivências de cada professor e de reflexão sobre o cotidiano docente trazido para o debate no curso. Identificamos essa concepção de contextualização como relação do cotidiano com o conhecimento científico também nas produções das sequências didáticas dos professores participantes do curso. Identificamos outras concepções de contextualização nessas produções dos professores participantes, mas com menor frequência.

Para tanto, buscou-se uma abordagem interdisciplinar desses temas, articulando as diferentes áreas do conhecimento em torno de problemáticas ambientais e temas transversais. Essa articulação esteve presente não só na proposta pedagógica do curso como também na escolha da equipe multidisciplinar de professores que ministrou as oficinas e nos professores participantes do curso. A ideia foi promover diferentes olhares disciplinares na compreensão de fenômenos e problemas de ordem socioambiental e global.

Outro aspecto bastante presente no PP do curso é levantar discussões sobre a relação entre ciência, tecnologia e sociedade (CTS) na elaboração de atividades didáticas. A produção dessas atividades envolveu uma ampla reflexão sobre o uso dos recursos naturais, tais como água, diversidade biológica e matrizes energéticas, por meio da tecnologia, e suas implicações para a sociedade. Nesse percurso, diferentes pontos de vista foram considerados, o que implicou abordagens nos contextos histórico, cultural e social.

Em relação às sequências didáticas (SDs), que representam a produção coletiva dos professores ao longo do curso, foram identificadas concepções de CE que se enquadram basicamente na categoria do "cotidiano do aluno". As SDs apresentavam questões locais do município com o intuito de trazer para a pauta da discussão situações vivenciadas no dia a dia pelos estudantes e questões relativas ao mundo do trabalho, ao mundo produtivo e aos seus impactos. Duas outras categorias - das "disciplinas escolares" e dos "contextos histórico, cultural e social" - foram encontradas nas SDs, porém pontualmente e de forma pouco significativa.

$\mathrm{Na}$ primeira sequência didática, cujo tema é "Matrizes Energéticas", identificou-se um enfoque no risco do apagão, ocorrido em 2000, alertando-se para a necessidade da diversificação e ampliação dos recursos energéticos. A discussão sobre novas fontes energéticas parte, assim, de uma questão presente no cotidiano e na sociedade atual. De acordo com o Quadro 1, essa 
abordagem encontra-se na perspectiva do cotidiano, na qual o ensino deve partir de situações concretas, da realidade do aluno e de seu contexto de significação.

Nessa SD, propõe-se ainda um texto para embasamento teórico dos alunos, que trata de todos os tipos de matrizes energéticas existentes e do seu histórico de utilização pelo homem, demonstrando a evolução nas tecnologias de produção de energia ao longo do tempo. Nesse texto, a contextualização se enquadra em outra categoria, a dos contextos histórico, social e cultural. Sugere ainda a necessidade de se relacionar ou situar o conhecimento específico no contexto de outras disciplinas escolares - Português, Matemática e Geografia -, propondo uma abordagem interdisciplinar.

$\mathrm{Na}$ segunda sequência didática, cujo tema é "água", propõe-se uma série de experimentos sobre resfriamento do ambiente, calor específico e armazenamento de calor, buscando-se responder à seguinte situação-problema: os aprendizes devem encontrar alternativas para o resfriamento do ambiente com menor consumo de água. Há ainda uma atividade envolvendo o plantio de mudas no horto florestal de Batatais, seguida de uma discussão sobre o papel de áreas verdes em centros urbanos. Apostilas sobre o consumo e distribuição da água no Brasil e no mundo, a construção de um condicionador de ar ecológico e o plantio de mudas são indicados para subsidiar essas atividades. Para finalizar, o texto propõe a realização de uma dramatização sobre a água, demonstrando como esse recurso natural está presente em todos os ambientes da Terra e nos seres vivos, e sobre o seu uso, que é exemplificado em situações diárias.

$\mathrm{Na}$ terceira sequência didática, cujo tema é "áreas verdes", propõe-se uma aula teórica sobre espécies de plantas indicadas para a construção de áreas verdes urbanas, um jogo de tabuleiro, um jogo da memória, um experimento de construção de um terrário e uma caminhada ecológica em torno da escola. Textos sobre a construção de um terrário, espécies indicadas para o plantio de áreas verdes urbanas, o papel das áreas verdes urbanas e aspectos do entorno da escola e da cidade foram subsídios importantes para essas atividades. No trecho "incentivar o estudo das áreas verdes partindo de locais próximos à realidade e ao entorno das escolas, considerando também as áreas verdes na cidade [...] tendo uma visão mais abrangente da vegetação brasileira e das modificações causadas pela ação do homem para com o meio ambiente", identifica-se uma concepção de CE na perspectiva do cotidiano do aluno, já que se enfatiza a importância de áreas verdes para a qualidade de vida da cidade em que se vive e o papel do conhecimento científico sobre arborização na compreensão dessa importância.

Com base nas concepções de CE encontradas nas três sequências didáticas analisadas, nota-se que estas se enquadram na perspectiva do "cotidiano do aluno" e, pontualmente, na perspectiva das "disciplinas escolares", já que a interdisciplinaridade aparece em todas elas como sugestão, e na perspectiva dos "contextos histórico, cultural e social", principalmente nas apostilas que subsidiam as atividades propostas. A perspectiva de contextualizar o ensino aproximando os conteúdos do cotidiano dos educandos oferece vantagens e tem implicações nas quais o professor deve prestar atenção.

\section{Considerações finais}

A diversidade de concepções de CE pode oferecer ao professor possibilidades múltiplas de mediações didáticas em sua difícil tarefa de planejar e organizar o ensino, desde que ele possa 
explicitar e explorar essas concepções nos processos de transposição do ensino. Foi nesse contexto que o presente estudo se realizou, identificando concepções de CE presentes em um curso de educação ambiental destinado à formação continuada de professores de diferentes áreas da educação básica. Os resultados deste estudo demonstraram que, apesar de o projeto pedagógico do curso propor diferentes perspectivas de abordagem desta importante diretriz metodológica para o ensino - a contextualização do ensino -, as sequências didáticas produzidas pelos professores participantes apresentaram basicamente uma perspectiva, a do cotidiano do aluno. É importante que os professores ampliem o seu conceito de CE e introduzam em suas atividades e práticas educativas as demais perspectivas dessa importante diretriz para o ensino.

Quanto à perspectiva predominante, a do cotidiano do aluno, é importante atentar para algumas das implicações pedagógicas que esta oferece para as práticas educativas. A valorização do cotidiano no ensino de Ciências não representa nenhuma novidade, pois, já no final da década de 1970, foram feitas no Brasil as primeiras manifestações sistemáticas a favor dessa ideia. Segundo Fracalanza, Amaral e Gouveia (1986), essa ideia pode ser concebida sob duas formas: aplicação do aprendizado na solução de problemas práticos na vida do estudante e uso do cotidiano como motivação para o aluno, já que, ao partir de seu mundo concreto, o aluno se interessaria mais pelo objeto de estudo e aprenderia mais. É importante ressaltar que a segunda forma não necessariamente exclui a primeira. Entretanto, os autores consideram que tanto um caminho quanto o outro cometem equívocos que devem ser enfrentados. Em primeiro lugar, os conteúdos escolares não devem ter compromisso prioritário com a utilidade imediata, mas com a formação intelectual do aluno, ficando as aplicações práticas imediatas como vantagens adicionais. Em segundo, não se deve considerar o cotidiano do aluno apenas como recurso motivacional, deve-se buscar, sempre que possível, uma articulação desse cotidiano com as demais fases da aprendizagem. Em terceiro, não se deve aceitar uma ideia de cotidiano padronizada e estereotipada, constituindo-se a própria negação do conceito de cotidiano, já que, para muitos deles, este é irreal e abstrato. As relações estabelecidas com o cotidiano do aluno devem permitir dar significado ao conteúdo curricular, fazendo a ponte entre o que se aprende na escola e o que se faz, vive e observa no dia a dia.

$\mathrm{Na}$ educação para as Ciências, o ensino contextualizado é condição necessária para formar cidadãos críticos, capazes de atuar no meio em que vivem e, ao mesmo tempo, de compreender a abordagem científica. Com relação à educação ambiental, não há como preparar os educandos para atuar nas relações entre o homem, a sociedade e o meio ambiente sem que eles se sintam parte de todo o processo. Ao se ensinarem conteúdos relacionados a essas temáticas, preocupando-se com a formação dos educandos e almejando que desenvolvam uma consciência crítica do mundo, é imprescindível que se promova um ensino contextualizado, pois somente encontrando significado no que aprende é que cada pessoa pode sentir-se parte do meio ambiente, com ele interagir e sobre ele atuar.

\section{Referências}

BARDIN, Laurence. Análise de conteúdo. Lisboa: Edições 70, 2009.

BRASIL. Ministério da Educação. SECAD. Diretoria de Educação para a Diversidade e Cidadania. Coordenação Geral de Educação Ambiental. Proposta de Diretrižes Curriculares Nacionais para a Educação Ambiental. Brasília: MEC/SECAD. Disponível em: <http://portal.mec.gov.br/dmdocuments/publicacao13.pdf>. Acesso em: 10 ago. 2010.

BRASIL. Ministério da Educação. Conselho Nacional de Educação. Diretrizes Curriculares Nacionais para o Ensino Médio. Brasília: MEC/CNE, 1998. 
BRASIL. Lei $n^{\circ}$ 9.795, de 27 de abril de 1999. Dispõe sobre a educação ambiental, institui a Política Nacional de Educação Ambiental e dá outras providências. Disponível em:

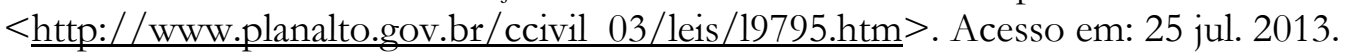

BRASIL. Secretaria de Educação Fundamental. Parâmetros Curriculares Nacionais: Meio Ambiente. Brasília, DF: $1997 . \quad$ MEC, Disponível em: <http://portal.mec.gov.br/seb/arquivos/pdf/meioambiente.pdf>. Acesso em: 10 ago. 2010.

BRASIL. Ministério da Educação. Secretaria de Educação Fundamental. Parâmetros Curriculares Nacionais: Ciências Naturais. Brasília: MEC/SEF, 1998.

CARVALHO, Isabel Cristina de Moura. Invenção e auto-invenção na construção psicossocial da identidade: a experiência constitutiva do educador ambiental. In: GUIMARÃES, Mauro (Org.). Caminhos da educaşão ambiental: da forma à ação. Campinas: Papirus, 2006. p. 31-50.

DIAS, Genebaldo Freire. Educação ambiental: princípios e práticas. 9. ed. São Paulo: Gaia, 2004.

FRACALANZA, Hilário; AMARAL, Ivan Amorosino; GOUVEIA, Mariley Simões Flória. O ensino de ciências no primeiro grau. São Paulo: Atual, 1986.

GUIMARÃES, Mauro. A formação de educadores ambientais. 3. ed. Campinas: Papirus, 2007.

GUIMARÃES, Mauro. Armadilha paradigmática na educação ambiental. In: LOUREIRO, Carlos Frederico Bernardo; LAYRARGUES, Philippe Pomier; CASTRO, Ronaldo Souza de (Org.). Pensamento complexo, dialética e educação ambiental. São Paulo: Cortez, 2006. p. 15-29.

KATO, Danilo Seithi. O significado da contextualização no ensino de ciências: análise dos documentos curriculares oficiais e de professores. In: ENCONTRO NACIONAL DE PESQUISA EM EDUCAÇÃO EM CIÊNCIAS, 6., 2007, Florianópolis. Anais... Florianópolis: UFSC, 2007.

KATO, Danilo Seithi; KAWASAKI, Clarice Sumi. As concepções de contextualização do ensino em documentos curriculares oficiais e de professores de ciências. Ciência \& Educação, v. 17, n. 1, p. 35-50, 2011.

LEME, Taciana Neto. Conhecimentos práticos dos professores e sua formação continuada: um caminho para a educação ambiental na escola. In: GUIMARÃES, Mauro (Org.). Caminhos da educação ambiental: da forma à ação. Campinas: Papirus, 2006. p. 87-115.

LIMA, Jozária de Fátima Lemos de; PINA, Maria do Socorro Lopes; BARBOSA, Rejane Martins Novais; JÓFOLI, Zélia Maria Soares. A contextualização no ensino de cinética química. Química Nova na Escola, Rio de Janeiro, n. 11, p. 27-29, 2000.

LOPES, Alice Casimiro. Os parâmetros curriculares nacionais para o ensino médio e a submissão ao mundo produtivo: o caso do conceito de contextualização. Educação \& Sociedade, Campinas, v. 23, n. 80, p. 386-400, 2002.

LOPES, Alice Casimiro; GOMES, Maria Margarida; LIMA, Inilcéa dos Santos. Diferentes contextos na área de Ciências da natureza, matemática e suas tecnologias dos Parâmetros Curriculares Nacionais do ensino médio: integração com base no mercado. In: ENCONTRO 
NACIONAL DE PESQUISA EM EDUCAÇÃO EM CIÊNCIAS, 3., 2001, Atibaia. Anais... Atibaia, SP: ABRAPEC, 2001.

MOURA, Dante Henrique; GARCIA, Sandra Regina de Oliveira; RAMOS, Marise. Educação profissional técnica de nivel médio integrada ao ensino médio. Brasília: 2007. Disponível em: < http://portal.mec.gov.br/setec/arquivos/pdf/documento base.pdf>. Acesso em: 05 jul. 2011.

MOYSÉS, Lucia. Aplicações de Vigotsky à educação matemática. Campinas: Papirus, 1997.

RODRIGUES, Carmen Lúcia; AMARAL, Marise Basso. Problematizando o óbvio: ensinar a partir da "realidade do aluno". REUNIÃO ANUAL DA ASSOCIAÇÃO NACIONAL DE PÓS-GRADUAÇÃO E PESQUISA EM EDUCAÇÃO, 19., Caxambu, 1996. Anais... Caxambu: ANPEd, 1996.

SATO, Michèle; CARVALHO, Isabel Cristina de Moura (Org.). Educação Ambiental: pesquisa e desafios. Porto Alegre: Artmed, 2005.

ZABALA, Antoni. A prática educativa: como ensinar. Trad. Ernani F. da F. Rosa. Porto Alegre: Artmed, 1998. 